\title{
NUMERICAL SIMULATION OF EFFECTS OF NUMBER OF BEDS AND PRESENCE OF AEROSOL FLOW FROM SANITATION MACHINE TO AIR CIRCULATION IN HOSPITAL ISOLATION ROOM OF COVID-19 PATIENTS
}

\author{
NARARYYA ZUFAR EL AZMI* \\ Department of Materials and Metallurgical Engineering, \\ Institut Teknologi Sepuluh Nopember, \\ Kampus ITS Sukolilo, 60111, Surabaya, East Java, Indonesia \\ nararyyazufar@gmail.com \\ MAS IRFAN P. HIDAYAT \\ Department of Materials and Metallurgical Engineering, \\ Institut Teknologi Sepuluh Nopember, \\ Kampus ITS Sukolilo, 60111, Surabaya, East Java, Indonesia \\ irfan@mat-eng.its.ac.id \\ AZZAH DYAH PRAMATA \\ Department of Materials and Metallurgical Engineering, \\ Institut Teknologi Sepuluh Nopember, \\ Kampus ITS Sukolilo, 60111, Surabaya, East Java, Indonesia \\ azzah@its.ac.id \\ * Corresponding author
}

Received 6 August 2021; Published 30 November 2021

\begin{abstract}
Coronavirus Disease (Covid-19) becomes a serious attention because the virus can spread from human-to-human rapidly. By the first case at December 2019, Covid-19 was making the outbreak all over the world just in few months, especially since February 2020 until now. As a result, the pandemic makes hospital occupancy really high. Hospital must make strategy to make sure the isolation rooms are sterile. By knowing the best configuration for the isolation room and sanitizing machine for spreading disinfectant aerosol, modelling can be used to minimize the high risk from the virus inside the room, as the virus can be transmitted in the airborne. In this study, CFD modelling is used to answer this problem by modelling 3 rooms with different amount of beds. Room 1 contains of 2 beds, room 2 contains of 3 beds and room 3 contains of 6 beds. SST k- $\varepsilon$ equation is used to model the flows. It is observed that the room with 6 beds has the biggest turbulence kinetic energy and high turbulence will be the best effective way to distribute aerosol from sanitizer to entire room.
\end{abstract}

Keywords: Covid-19; Isolation Room; CFD Modelling; Airflow; Turbulence.

\section{Introduction}

Coronavirus Disease (Covid-19) reported its first case at Wuhan, China, on December 2019. Just in few months, outbreak of the Covid-19 happening worldwide. The virus transmits by contact with droplet nuclei of size _ $<5$ $\mu \mathrm{m}$. (Cui, 2019) The virus also can transmit by inhalation within close contact to infected person. (Bhagat, 2020) The virus also can transmit during sneezing, coughing and even speaking by infected persons. This make Covid19 spread rapidly all over the world and make bed occupancy in hospitals are high. (Allam, 2020).

Considering the environment inside the isolation room is the most important part for hospital. By using various amount bed inside a room and aerosol from sanitizing machine for treatment of confirmed Covid-19 patients, hospital can decide which one is the best configuration for isolation room (Das, 2020). It's reasonable to investigate the effectiveness of air from the Air-Conditioner to mix with aerosol from sanitizing machine by using CFD analysis to compute turbulent kinetic energy and airflow dynamics (Adeniran, 2020). 
Azmi et. al.

\section{Flow Simulation}

Finite element method (FEM) is commonly employed for solving multi-physics problem (Syahroni and Hidayat, 2011). In this study, CFD by using ANSYS is used for simulating flow condition inside the isolation room. It is known that there are 3 kinds of flows based on Reynolds Number, there are: Laminar, Transition, and Turbulent. Laminar happens when the value or $\mathrm{R}<2000$. Transition happens when the value $\mathrm{R}$ between 2000 and 4000 $(2000<\mathrm{R}<4000)$. Turbulent happens when R $>4000$ (Menon, 2015). In this study, the turbulent model applied for the simulation for the room.

The dimensions for this modelling originally taken from a hospital, within length, breadth, and height respectively are $9144 \mathrm{~mm}, 6096 \mathrm{~mm}$, and $3658 \mathrm{~mm}$. Also, the dimension of other components for simulation has been considered for simulation. Those components are beds (1219 mm x $1828 \mathrm{~mm}$ x $2134 \mathrm{~mm})$, AC vent (1000 mm x $1000 \mathrm{~mm})$, exhaust vent (1800 mm x $300 \mathrm{~mm})$, sanitizing machine (1524 mm x $1328 \mathrm{~mm}$ x $1219 \mathrm{~mm})$, and door (1234 mm x $1046 \mathrm{~mm})$. Inlet condition also important for this study. The specification for AC vent is with a velocity of $3.91 \mathrm{~m} / \mathrm{s}$ applied uniformly within inlet temperature of $24^{\circ} \mathrm{C}$. For the sanitizing machine specification, velocity is at $1.5 \mathrm{~m} / \mathrm{s}$ applied uniformly within inlet temperature of $30^{\circ} \mathrm{C}$. Boundary conditions are applied in this simulation, there are: no-slip and no-temperature jump conditions at the exit of the ducting system to get the optimum result. (Bhattacharyya, 2020). Fig. 1 shows the hospital isolation room model within the component inside the room, such as door, exhaust vent/outlet, AC, and patient beds.

By using the transition SST k- $\varepsilon$ equation, the numerical model for laminar-transitional flows can be done numerically. The special transition $\mathrm{k}-\varepsilon$ model is formed by combination of SST $\mathrm{k}-\omega$ models with two additional transport equations which are listed below:

k-equation

$\omega$-equation

$$
\frac{\partial}{\partial t}(\rho k)+\frac{\partial}{\partial x_{j}}\left(\rho k u_{i}\right)=\frac{\partial}{\partial x_{j}}\left(\Gamma_{k} \frac{\partial k}{\partial x_{j}}\right)+G_{k}-Y_{k}-S_{k}
$$

$$
\frac{\partial}{\partial t}(\rho \omega)+\frac{\partial}{\partial x_{j}}\left(\rho \omega u_{i}\right)=\frac{\partial}{\partial x_{j}}\left(\Gamma_{k} \frac{\partial \omega}{\partial x_{j}}\right)+G_{\omega}-Y_{\omega}+D_{\omega}+S_{w}
$$

$\gamma$-equation

$$
\frac{\partial(\rho \gamma)}{\partial t}+\frac{\partial\left(\rho U_{j} \gamma\right)}{\partial x_{j}}=P_{\omega}-E_{\omega}+P_{\omega}-E_{w}+\frac{\partial}{\partial x_{j}}\left[\left(\mu+\frac{\mu_{t}}{\sigma_{y}}\right) \frac{\partial y}{\partial x_{j}}\right]
$$

$\operatorname{Re} \theta_{\mathrm{t}}$-equation

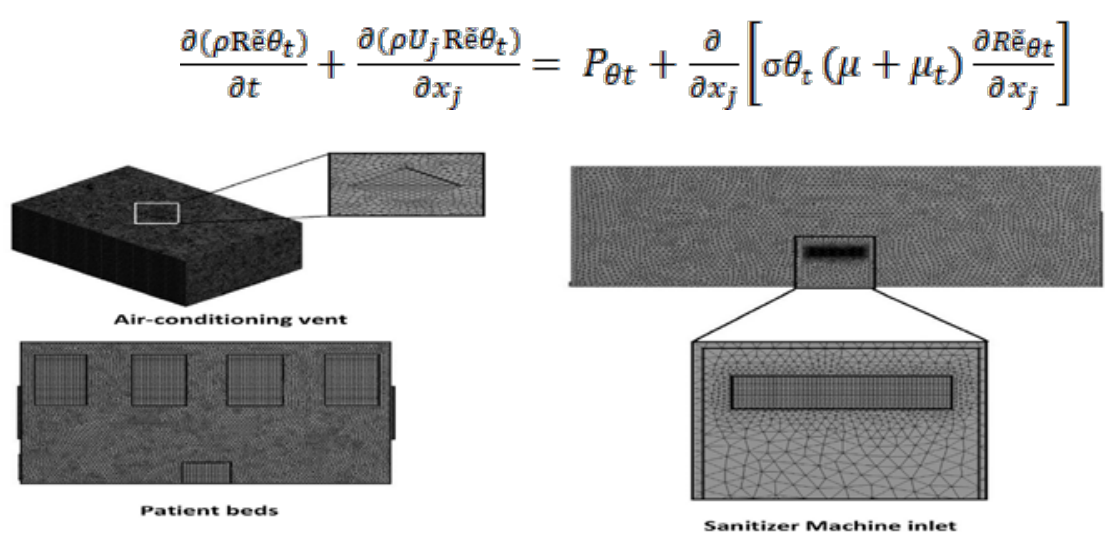

Fig 1. Meshing from the hospital components

Fig. 2 shows the configuration of each room used in the simulation design shown in Table 1. 
Azmi et. al.

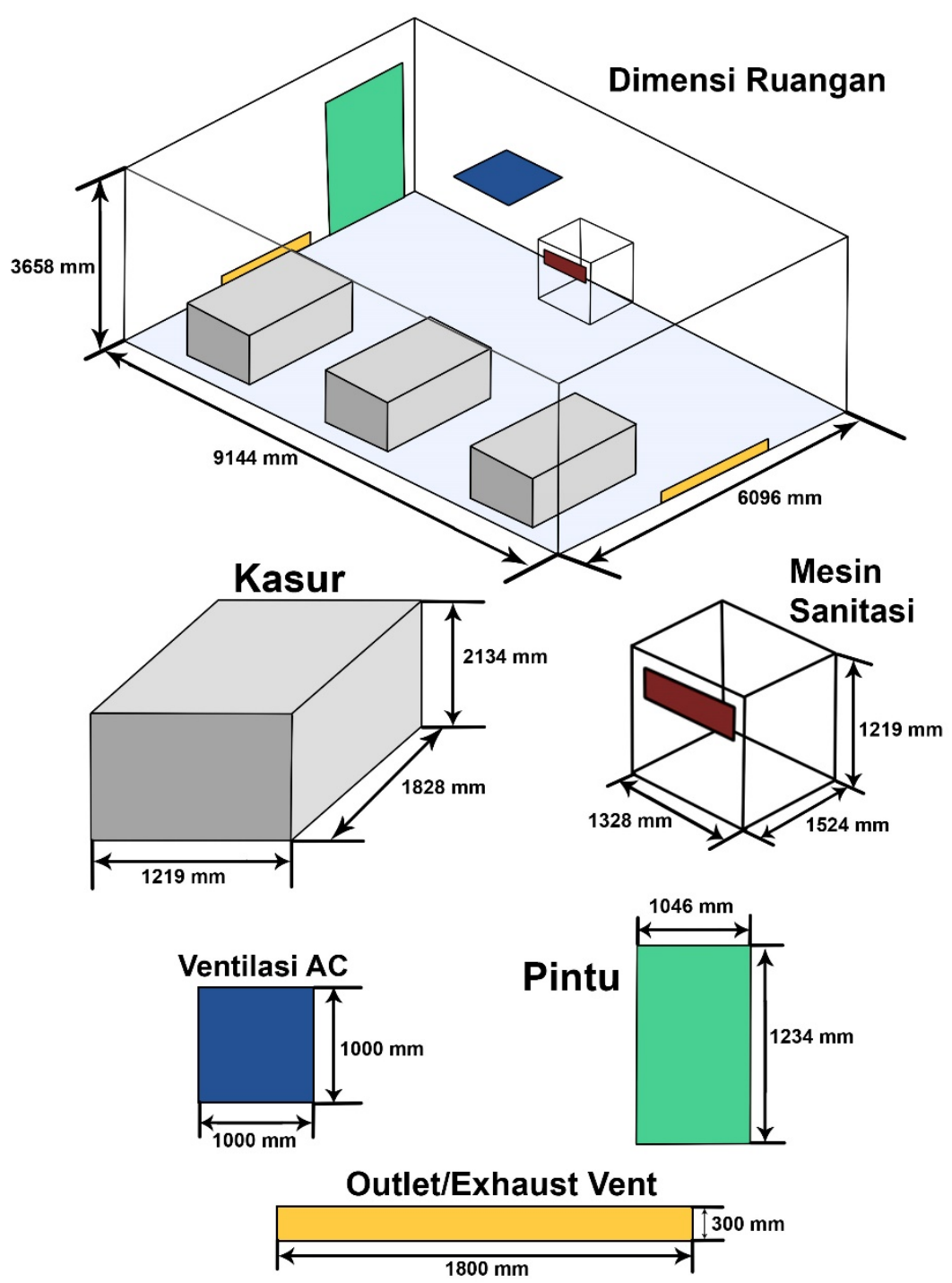

Fig 2. Size of each component

\section{Numerical Implementation}

Drawing each room for simulation are necessary for this. There are 6 rooms in total of the simulation, which 3 rooms contains no sanitizer, while the rest of them are the room with sanitizer. Fig 3 illustrated all the rooms configuration

\subsection{Design of Simulation}

Before heading to the simulation, it must know what are the achievement for this simulation. Based on the resources, the most important part. Table 1 shows the simulation plan that contains amount of bed, variations, and the output for this simulation. 
Azmi et. al.

Table 1. Simulation Design

\begin{tabular}{|c|c|c|}
\hline Variable & Variations & Output \\
\hline 2 Beds & Without Sanitizer & $\begin{array}{c}\text { Turbulence Kinetic Energy } \\
\left(\mathrm{m}^{2} / \mathrm{s}^{2}\right)\end{array}$ \\
\cline { 2 - 2 } & With Sanitizer & \\
\hline 3 Beds & Without Sanitizer & \\
\cline { 2 - 2 } & With Sanitizer & \\
\hline 6 Beds & Without Sanitizer & \\
\cline { 2 - 2 } & With Sanitizer & \\
\hline
\end{tabular}
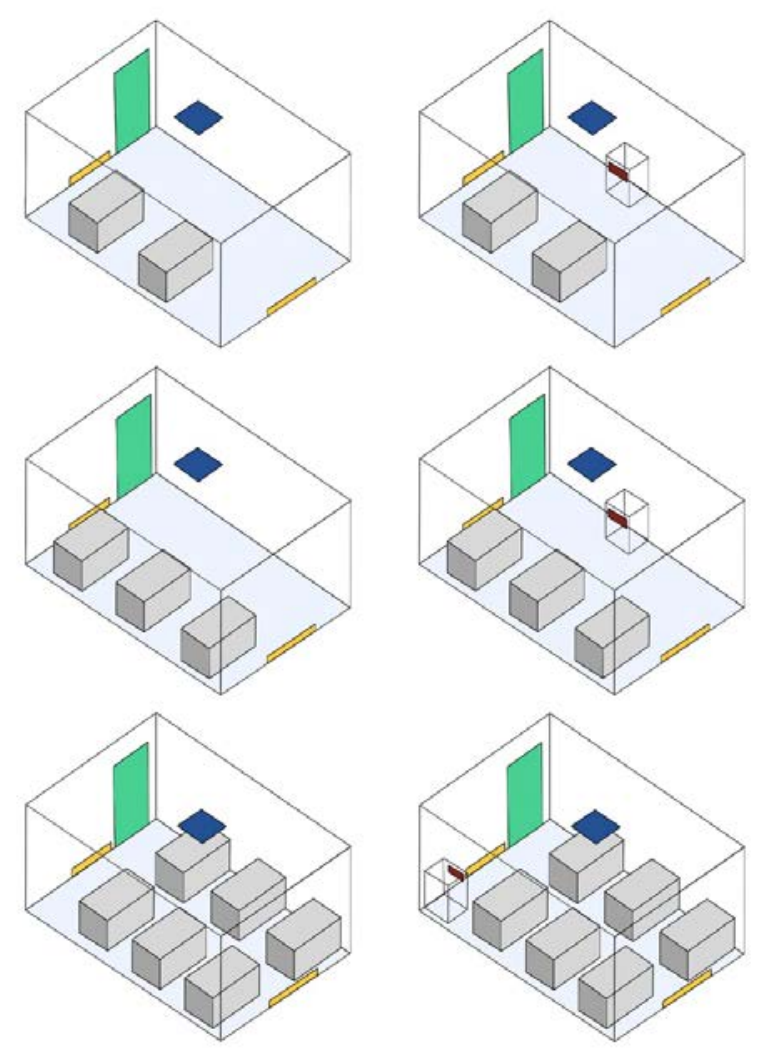

Fig. 3. (From left to right, up to down) configuration of Covid-19 patients' room that contains 2 beds without sanitizer, 2 beds with sanitizer, 3 beds without sanitizer, 3 beds with sanitizer, 6 beds without sanitizer, and 6 beds with sanitizer 
Azmi et. al.

\section{Results and Discussion}

CFD model accepted in this work to investigate indoor air quality, thermal comfort, performance of HVAC, etc. In this study, the purpose of CFDs are to investigate the airflow inside the patient room and also the value of turbulence kinetic energy of each rooms.
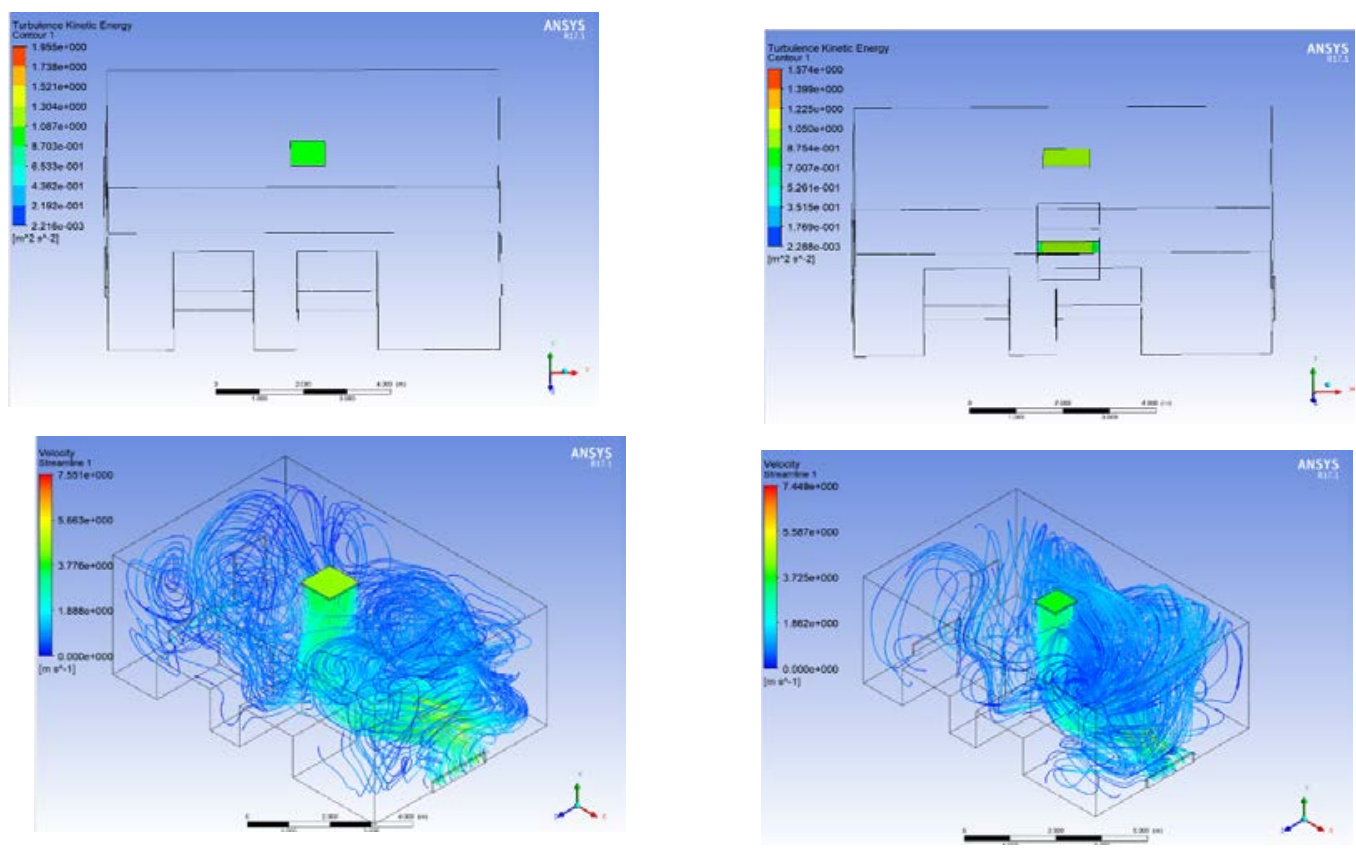

Fig 4. (From left to right, up to down) turbulence kinetic energy for 2 beds without sanitizing and with sanitizing. Also, the airflow from 2 beds without sanitizing and with sanitizing
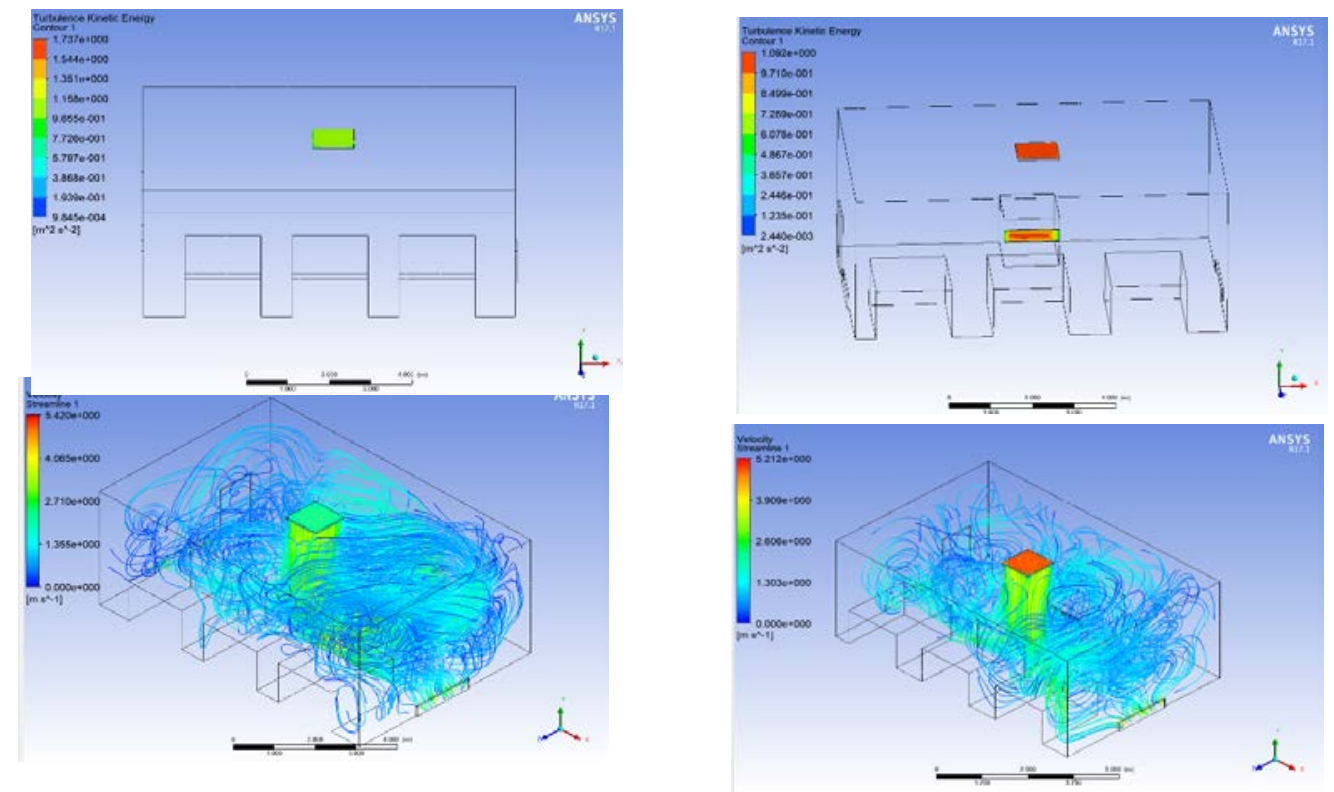

Fig 5. (From left to right, up to down) turbulence kinetic energy for 3 beds without sanitizing and with sanitizing. Also, the airflow from 2 beds without sanitizing and with sanitizing 
Azmi et. al.
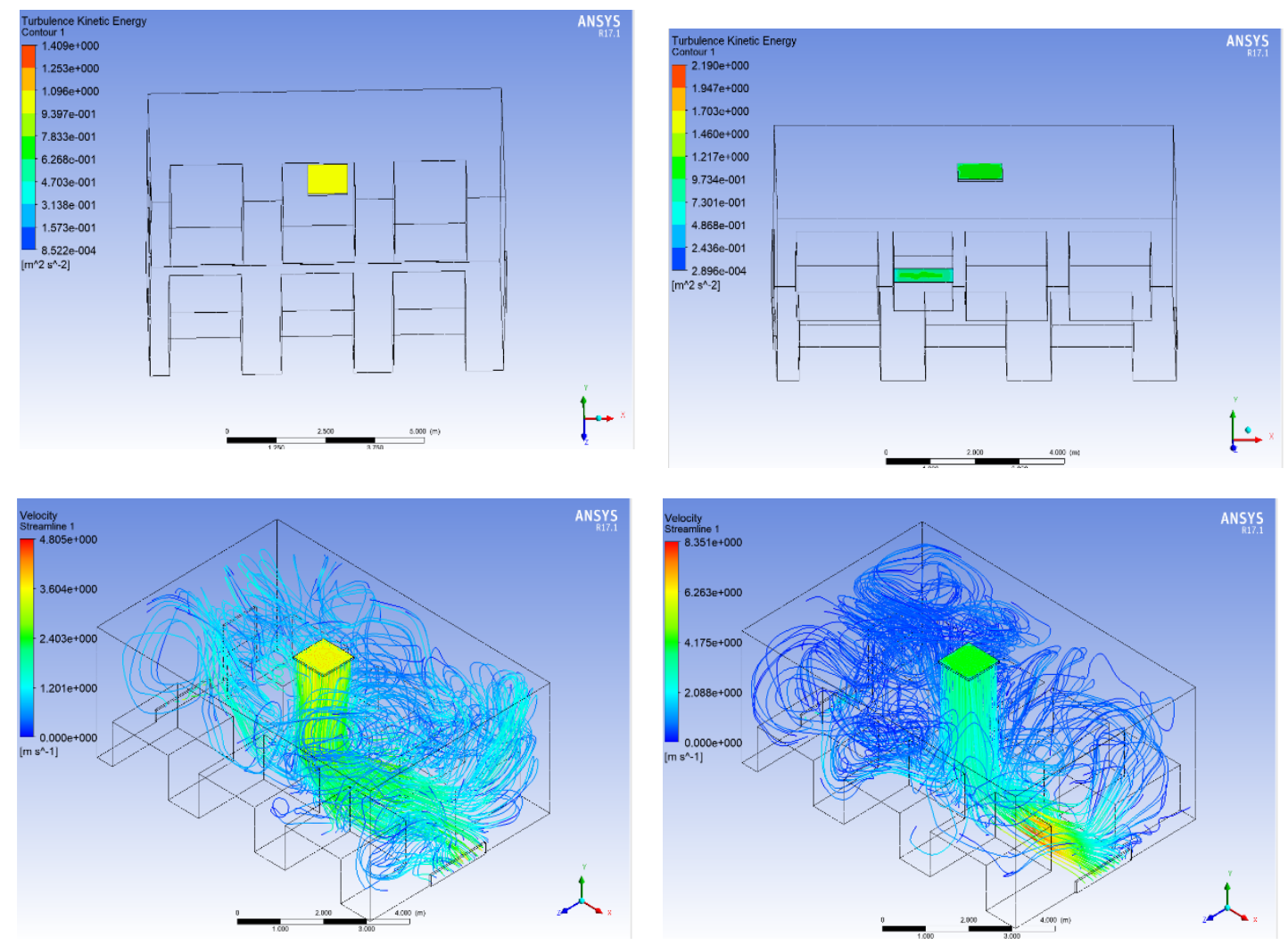

Fig 6. (From left to right, up to down) turbulence kinetic energy for 3 beds without sanitizing and with sanitizing. Also, the airflow from 2 beds without sanitizing and with sanitizing

Table 2 is the summary of the simulation results obtained in the present study. It can be seen that the room within 6 beds and sanitizing machine has impact for increasing the turbulence kinetic energy and also the airflow inside the room. These rooms use mixing ventilation because they are easy to applicated rather than displacement ventilation, although the result for the ventilation is better using displacement than mixing. (Blocken, 2020).

Table 2. Comparison of process/performance of method A and method B

\begin{tabular}{|l|l|l|}
\hline Variable & Variation & $\begin{array}{l}\text { Turbulence Kinetic Energy } \\
\left(\mathrm{m}^{2} / \mathrm{s}^{2}\right)\end{array}$ \\
\hline 2 Beds & Without Sanitizer & 1,955 \\
\cline { 2 - 3 } & With Sanitizer & 1,57 \\
\hline \multirow{2}{*}{3 Beds } & Without Sanitizer & 1,737 \\
\cline { 2 - 3 } & With Sanitizer & 1,092 \\
\hline 6 Beds & Without Sanitizer & 1,409 \\
\cline { 2 - 3 } & With Sanitizer & 2,190 \\
\hline
\end{tabular}


Distance for each bed are $700 \mathrm{~mm}$, while distance between the bed and the wall is $300 \mathrm{~mm}$. Increasing the number of beds will make the airflow bouncing around the room and going everywhere in the room. (Mirzaie, 2021) making various flow inside the room. It makes the turbulence energy high, so that's why 6 beds have the biggest turbulence kinetic energy. Besides, the velocity inside the room also increasing. While velocity increase, the aerosol will spread in the room faster and more efficient compared to the slower one. To make the velocity increase, the amount of bed must be increased too so the airflow will go to every corner side of the room and make the room sterilized. (Ahmazadeh, 2021).

\section{Conclusions}

The result of this simulation shows that 6 beds with sanitizer have the biggest turbulence kinetic energy and the highest airflow in the rooms. The sanitizer has an impact to increase the turbulence kinetic energy thus can make the airflow higher too. This can be a reference for the hospital to configure the best number of beds in the isolation room, but the room must contain sanitizer too. The sanitizer can also be a treatment for Covid-19 patients to make sure they are safe.

\section{Acknowledgments}

The authors are grateful for the support from Institut Teknologi Sepuluh Nopember Surabaya for this research.

\section{References}

Adeniran, J.A.; Mohammed, I.A.; Muniru, O.I.; Oloyede, T.; Sonibare, O.O.; Yusuf, M.O.; Abdulraheem K.A.; Odediran, E.T.; Yusuf, R.O.; Sonibare, J.A. (2020). Indoor transmission dynamics of expired SARS-CoV-2 virus in a model African hospital ward. Journal of Environmental Health Science and Engineering: University of Ilorin, Nigeria

Ahmazadeh, M.; Farokhi, E.; Shams, M. (2021). Investigating the effect of air conditioning on the distribution and transmission of COVID-19 virus particles. Journal of Cleaner Production 128147

Allam, Zaheer (2020). Surveying the Covid-19 Pandemic and Its Implications: Urban Health, Data Technology and Political Economy. Elsevier: Victoria, Australia; ISBN 978-0-12-824313-8

Bhagat, R.K.; Wykes, M.S.D.; Dalziel, S.B.; Linden, P.F. (2020). Effects of ventilation on the indoor spread of

COVID-19. Focus on Fluids: Cambridge University

Blocken, B.; Druenen, T. V.; Hooff, T.V.; Verstappen, P.A.; Marchal, T.; Marr, L.C. (2020). Can indoor sports centers be allowed to re-open during the COVID-19 pandemic based on a certificate of equivalence? Building and Environment 180107022

Bhattacharyya, S.; Dey, K.; Paul, A.R.; Biswas, R. (2020). A novel CFD analysis to minimize the spread of COVID-19 virus in hospital isolation room. Chaos, Solitons and Fractals, 139

Cui, J.; Li, F.; Shi, Z. (2019). Origin and evolution of pathogenic coronaviruses. Nat Rev Microbiol 17, 181-192

Das, S.K. (2020). The Pathophysiology, Diagnosis and Treatment of Corona Virus Disease 2019 (COVID-19). Indian J Clin Biochem 13;35(4):1-12

Filippini, T.; Rothman, K.J.; Goffi, A.; Ferrari, F.; Maffeis, G.; Orsini, N.; Vinceti, M. (2020). Satellite-detected tropospheric nitrogen dioxide and spread of SARS-CoV-2 infection in Northern Italy. Science of the Total Environment: Italy

Mirzaie, M.; Lakzian, E.; Khan, A.; Warkiani, M.E.; Mahian, O.; Ahmadi, G. (2021) COVID-19 spread in a classroom equipped with partition - A CFD approach. Journal of Hazardous Materials 420126587

Syahroni, N. and Hidayat, M.I.P. (2011), Numerical Simulation of Welding Sequence Effect on Temperature Distribution, Residual Stresses and Distortions of T-Joint Fillet Welds, Advanced Materials Research, Vols. 264-265, pp 254-259

Shashi Menon, E. (2015). Fluid Flow in Pipes. Transmission Pipeline Calculations and Simulations Manual, 149-234 